\title{
ADUBAÇÃO NITROGENADA PARA ALTO RENDIMENTO DE MILHO EM PLANTIO DIRETO NA REGIÃO CENTRO-SUL DO PARANÁ(1)
}

\author{
Sandra Mara Vieira Fontoura ${ }^{(2)}$ \& Cimélio Bayer ${ }^{(3)}$
}

\begin{abstract}
RESUMO
$\mathrm{O} \mathrm{N}$ é um dos nutrientes demandados em maior quantidade pela cultura do milho e o seu suprimento adequado tem implicações técnicas, quanto ao desempenho e à lucratividade da cultura, e ambientais pelo alto potencial de lixiviação do nitrato. Resultados de 61 experimentos, realizados por 13 anos, numa parceria entre a Fundação Agrária de Pesquisa Agropecuária (FAPA) e a Universidade Federal do Rio Grande do Sul (UFRGS), foram analisados e interpretados visando o desenvolvimento de uma tecnologia de indicação de $\mathrm{N}$ para alto rendimento da cultura do milho em plantio direto e adaptado ao uso de plantas de cobertura na região centro-sul do Paraná. As quantidades de N (ureia) a serem aplicadas no milho foram estimadas a partir da demanda de $\mathrm{N}$ em diferentes faixas de rendimento de grãos da cultura $(6-8,8,1-10,10,1-12$ e 12,1-14 t ha-1), da disponibilidade de $\mathrm{N}$ à cultura em solos com diferentes teores de matéria orgânica (MO) na camada de 0-10 cm $\left(<40,40-60\right.$ e $\left.>60 \mathrm{~g} \mathrm{~kg}^{-1}\right)$, do efeito de plantas de cobertura (gramínea, leguminosa, consórcio gramínea-leguminosa e nabo forrageiro) na disponibilidade de $\mathrm{N}$, e da eficiência do $\mathrm{N}$ mineral aplicado. As doses de $\mathrm{N}$ indicadas (DNI) tiveram boa relação com as doses de máxima eficiência econômica (DMEE) calculadas para condições distintas de MO no solo, planta de cobertura e expectativa de rendimento $\left(\mathrm{DNI}=39+0,80\right.$ DMEE, $\mathrm{R}^{2}=0,74, \mathrm{n}=20$, $p=0,03$ ), o que confirma a adequação das doses para a cultura na região. As doses também apresentaram boa relação com a indicação de $\mathrm{N}$ vigente nos Estados do RS e SC (DNI: PR = -14 + 1,06 RS/SC, $\left.R^{2}=0,88, n=12, p=0,02\right)$, o que valida o uso da indicação do centro-sul do PR, que apresenta expectativas de rendimento mais elevadas, para sub-regiões do RS/SC que apresentam alto potencial de rendimento da cultura. Da mesma forma, a indicação do RS/SC pode ser utilizada para subregiões do PR que apresentam menor aptidão climática à cultura do milho.
\end{abstract}

Termos de indexação: ureia, plantas de cobertura, matéria orgânica.

\footnotetext{
(1) Recebido para publicação em fevereiro de 2008 e aprovado em julho de 2009.

(2) Pesquisadora da Fundação Agrária de Pesquisa Agropecuária - FAPA. CEP 85139-400 Guarapuava (PR). E-mail: sandrav@agraria.com.br

(3) Professor do Departamento de Solos da Universidade Federal do Rio Grande do Sul - UFRGS. Caixa Postal 15100, CEP 91540000 Porto Alegre (RS). E-mail: cimelio.bayer@ufrgs.br
} 


\title{
SUMMARY: NITRONGEN-FERTILIZER RECOMMENDATION FOR HIGH CORN YIELDS UNDER NO-TILLAGE IN THE SOUTH-CENTRAL REGION OF PARANÁ STATE, BRAZIL
}

\begin{abstract}
Nitrogen $(N)$ is required in large quantities by corn and its supply causes technical concerns related to crop performance and profitability, and environmental concerns in view of the high risk of nitrate leaching. Results of 61 field experiments conducted through 13 years, in a cooperative effort of the Fundação Agrária de Pesquisa Agropecuária (FAPA) and the Universidade Federal do Rio Grande do Sul (UFRGS), were analyzed and interpreted aiming at establishing a $N$ fertilizer indication for high corn yields, adjusted to the use of winter cover crops in no-till soils in the South-Central region of Parana, Brazil. The urea-N rates were calculated based on the $N$ required for different corn yield levels (6-8, 8.1-10, 10.1-12 and 12.1$\left.14 t \mathrm{ha}^{-1}\right)$ and taking into account the $N$ availability in soils with different soil organic matter contents in the layer $0-10 \mathrm{~cm}\left(<40,40-60\right.$ and $\left.>60 \mathrm{~g} \mathrm{~kg}^{-1}\right)$, the effect of winter cover crops (grass, leguminous, grass-legume consortium, and wild radish) on $N$ availability, and the efficiency of $N$ fertilizer. The indicated rates of urea- $N$ were closely related to the $N$ rates for maximum economic efficiency (MEE) for different soil OM contents, cover crop and corn yield $\left(N\right.$ indication $\left.=39+0.80 M E E, R^{2}=0.74, n=20, p=0.03\right)$ corroborating the adequacy of this $N$ indication for corn. The $N$ rates were closely correlated with the rates recommended in the states of Rio Grande do Sul (RS) and Santa Catarina (SC) (Indication PR $=-14+1.06$ RS / $S C, R^{2}=0.88, n=12, p=0.02$ ). This confirms the use of the indication of Central South Parana for subregions of $R S$ and $S C$ with high corn yield potential. Likewise, the recommendation for $R S$ and SC can also be used in subregions in PR that are climatically less suitable for corn.
\end{abstract}

Index terms: $N$ fertilization, urea, cover-crops, organic matter.

\section{INTRODUÇÃO}

O milho é cultivado em aproximadamente $1,5 \mathrm{M}$ ha no Paraná (PR), com rendimento médio de aproximadamente $5 \mathrm{t} \mathrm{ha}^{-1}$ (Seab, 2008). Na região centro-sul do PR, têm-se obtido altos rendimentos, relacionados, entre outros fatores, à sua maior aptidão climática. A precipitação pluvial nessa região, no período de outubro-março, é em torno de $1.100 \mathrm{~mm}$, enquanto a temperatura média é de $18,5^{\circ} \mathrm{C}$ (IAPAR, 2008a,b), com ocorrência semanal de chuvas na primavera-verão (Fontoura, 2005). Em relação ao manejo do solo, a região centro-sul do PR apresentase em estágio avançado de adoção de sistemas conservacionistas, evidenciado pela grande expressão do sistema plantio direto (Fontoura, 2005). Diversos municípios apresentam quase a totalidade da área cultivada nesse sistema de manejo, o que, apesar da contínua necessidade de práticas complementares, mecânicas e vegetativas, para a conservação do solo, representa um referencial importante na conservação do solo e da água no sul do país, com expressivo efeito na melhoria da qualidade química, física e biológica do solo e na produtividade das culturas (Mielniczuk et al., 2003; Lovato et al., 2004).

As lavouras têm apresentado rendimentos médios de 9-10 t ha ${ }^{-1}$ em plantio direto (Fontoura, 2005), enquanto em áreas de pesquisa da Fundação Agrária de Pesquisa Agropecuária (FAPA), em Guarapuava $(\mathrm{PR})$, têm-se obtido rendimentos de até $18 \mathrm{t} \mathrm{ha}^{-1}(\mathrm{~N}$. Antoniazzi, comunicação pessoal). Esses elevados rendimentos de milho obtidos na pesquisa demonstram o potencial da cultura na região e a possibilidade de aumento de rendimento nas lavouras. Dentre os fatores que podem aumentar o rendimento do milho, destacam-se o manejo da fertilidade do solo e, em especial, o da adubação nitrogenada. A interpretação de resultados de diversos experimentos realizados na região tem indicado a dose de $150 \mathrm{~kg} \mathrm{ha}^{-1}$ de N-ureia como uma quantidade média a ser aplicada em cobertura na cultura do milho, visando a máxima eficiência econômica do fertilizante (Fontoura, 2005). Entretanto, nos diferentes experimentos, essa dose tem variado entre 40 e $240 \mathrm{~kg} \mathrm{ha}^{-1}$, o que tem sido atribuído à diferente capacidade de suprimento de $\mathrm{N}$ dos solos, da planta de cobertura utilizada no inverno anterior, e da oscilação no volume de chuvas que afeta o potencial de rendimento e a reposta da cultura ao adubo nitrogenado (Fontoura, 2005).

A adoção de diferentes plantas de cobertura como o nabo forrageiro, ervilhaca e aveia preta, em cultivo solteiro ou consorciado, tem aumentado na região como alternativas na rotação de culturas no inverno, principalmente com o trigo e a cevada (Fontoura, 2005; Fontoura \& Bayer, 2008). O efeito da ervilhaca e, mais recentemente, do nabo forrageiro no fornecimento de $\mathrm{N}$ para as culturas em sucessão é amplamente 
reconhecido (Bayer et al., 1998; Amado et al., 2000; Aita et al., 2004; Giacomini et al., 2004; Lovato et al., 2004), sendo de fundamental importância a sua consideração num sistema de indicação de $\mathrm{N}$ para o milho (Amado et al., 2002), como já vem sendo adotado nos Estados do RS e SC (Comissão... 2004).

Um sistema regional de indicação de $\mathrm{N}$ para o milho pode ser desenvolvido com base em quatro critérios essenciais: expectativa de rendimento da cultura, teor de matéria orgânica do solo, tipo de planta de cobertura antecessora, e eficiência de absorção do $\mathrm{N}$ aplicado. A expectativa de rendimento determina a demanda de $\mathrm{N}$ pela cultura, enquanto a matéria orgânica e a planta de cobertura afetam o suprimento de $\mathrm{N}$ para o milho. A partir da diferença entre demanda e suprimento de $\mathrm{N}$, pode-se estimar a quantidade de $\mathrm{N}$ a ser aplicada, levando-se em consideração também a eficiência do adubo nitrogenado aplicado (Fernandes, 1998; Amado et al., 2002; Fontoura \& Bayer, 2008).

Este estudo consistiu na análise e interpretação de resultados de 61 experimentos de $\mathrm{N}$ em milho, desenvolvidos pela Fundação Agrária de Pesquisa Agropecuária em parceria com a Universidade Federal do Rio Grande do Sul, e teve como objetivo o estabelecimento de tecnologia de indicação de $\mathrm{N}$ para alto rendimento de milho em plantio direto e adaptada ao uso de plantas de cobertura de inverno na região centro-sul do PR.

\section{MATERIAL E MÉTODOS}

\section{Localização e caracterização edafoclimática da região de estudo}

Este estudo foi realizado na região centro-sul do PR, que abrange 19 municípios (Figura 1). A região apresenta predominância de Nitossolos e Latossolos (Embrapa, 1999), e a altitude varia entre 550 e $1.100 \mathrm{~m}$ (IAPAR, 2008b). A classificação climática predominante, segundo Köppen, é Cfb, com precipitação pluvial anual de 1.600 a $2.000 \mathrm{~mm}$. A frequência de chuvas é semanal no período de outubro a março, com um volume médio mensal de $178 \mathrm{~mm}$, e baixa frequência de veranicos (IAPAR, 2008a; Fontoura, 2005). A temperatura média mensal oscila entre 12,5 (julho) e $20,5^{\circ} \mathrm{C}$ (janeiro), sendo a temperatura média anual de $16,8^{\circ} \mathrm{C}$ (IAPAR, 2008a,b; Fontoura, 2005).

\section{Experimentos}

Um total de 61 experimentos relacionados com a adubação nitrogenada na cultura do milho foram realizados no período de 13 anos (1994/1995 a 2007/ 2008), envolvendo fatores como doses de N, plantas de cobertura, população de plantas, híbridos, fontes de $\mathrm{N}$ e época de aplicação (Quadro 1). Em sua grande

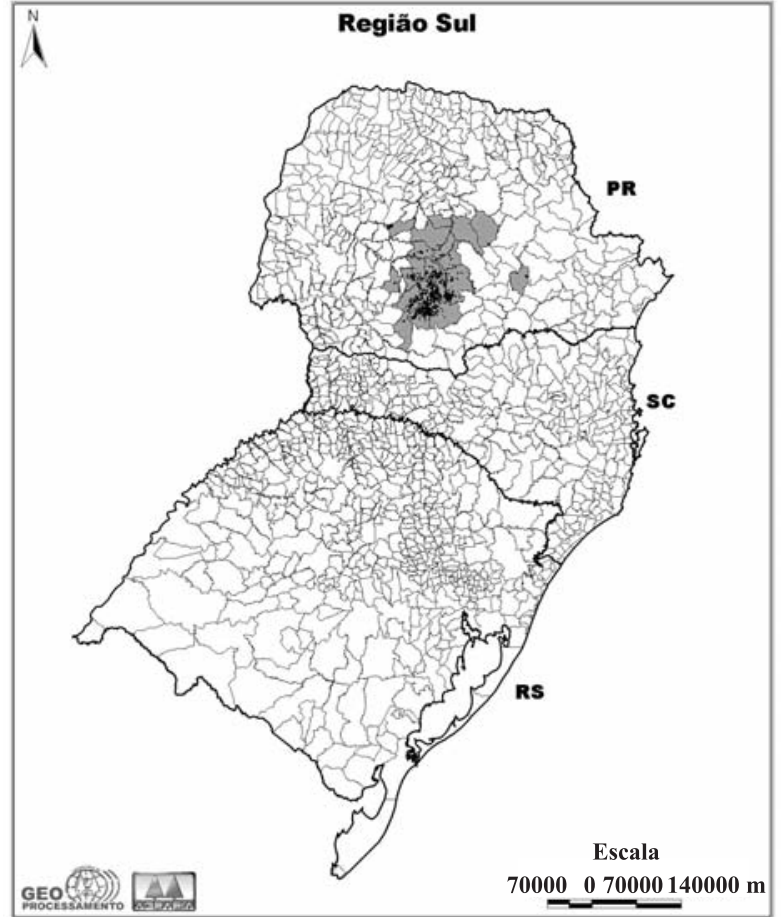

Figura 1. Divisão política (municípios) dos Estados que compõem a região sul do Brasil e localização (em cinza) da região centro-sul do $P R$, na qual foi desenvolvida a pesquisa.

maioria, os experimentos foram desenvolvidos na área experimental da Fundação Agrária de Pesquisa Agropecuária (FAPA), no distrito de Entre Rios, Guarapuava (PR), mas, nos últimos quatro anos, a pesquisa foi desenvolvida em mais três municípios (Candói, Pinhão e Teixeira Soares) visando abranger maior variedade de tipos de solo e de condições climáticas.

Todos os experimentos na área experimental da FAPA foram realizados em sistema de plantio direto com 7 a 20 anos de duração. Nas áreas de produtores, os experimentos foram realizados em áreas que estavam 25-30 anos em plantio direto (Quadro 1). Os experimentos de doses de $\mathrm{N}$ foram realizados todos em delineamento de blocos casualizados, com três repetições. Quando da existência de mais de um fator, utilizou-se para os níveis do segundo fator parcelas subdivididas (Quadro 1).

\section{Fundamentos e métodos empregados para elaboração do sistema de indicação de $\mathbf{N}$}

O desenvolvimento do método empregado para elaboração do sistema de indicação de $\mathrm{N}$ para o milho foi fundamentado no fato de que as fontes de suprimento do $\mathrm{N}$ para o milho (Zea mays L.) são o solo, a planta de cobertura e o adubo nitrogenado, segundo a equação (1). 
Quadro 1. Síntese das informações referentes aos experimentos

\begin{tabular}{|c|c|c|c|c|c|c|c|c|c|}
\hline \multirow{2}{*}{$\begin{array}{c}\text { Ano } \\
\text { agrícola }\end{array}$} & \multirow{2}{*}{ Local } & \multicolumn{2}{|r|}{ Experimentos } & \multirow{2}{*}{$\begin{array}{c}\text { Anos } \\
\text { em PD }\end{array}$} & \multicolumn{5}{|c|}{ Características de fertilidade do solo } \\
\hline & & $\mathrm{N}^{\mathrm{o}}$ & Fatores e Níveis & & $\mathbf{C}$ & $\mathrm{pH}_{\mathrm{CaCl}_{2}}$ & $\mathbf{K}$ & $\mathbf{P}$ & $\mathrm{V}$ \\
\hline & & & & & $\mathrm{g} \mathrm{kg}^{-1}$ & & $\mathrm{cmol}_{\mathrm{c}} \mathrm{dm}^{-3}$ & $\mathrm{mg} \mathrm{dm} \mathrm{m}^{-3}$ & $\%$ \\
\hline $1994 / 1995$ & Guarapuava & 1 & $\begin{array}{l}\text { Doses N-ureia }(0,50,100,150 \text { e } \\
\left.200 \mathrm{~kg} \mathrm{ha}^{-1}\right) \text {, híbridos }(7)\end{array}$ & 07 & 28,78 & 5,25 & 0,46 & 19,65 & 57,55 \\
\hline $1995 / 1996$ & Guarapuava & 1 & $\begin{array}{l}\text { Doses N-ureia }(0,50,100,150 \text { e } \\
\left.200 \mathrm{~kg} \mathrm{ha}^{-1}\right) \text {, híbridos (8) }\end{array}$ & 08 & 40,70 & 5,25 & 0,62 & 19,80 & 59,70 \\
\hline $1996 / 1997$ & Guarapuava & 1 & $\begin{array}{l}\text { Doses N-ureia ( 0, 50, 100, } 150 \text { e } \\
\left.200 \mathrm{~kg} \mathrm{ha}^{-1}\right) \text {, híbridos (7) }\end{array}$ & 09 & 35,75 & 4,60 & 0,33 & 13,40 & 37,55 \\
\hline $1997 / 1998$ & Guarapuava & 1 & $\begin{array}{l}\text { Doses N-ureia }(0,50,100,150 \mathrm{e} \\
\left.200 \mathrm{~kg} \mathrm{ha}^{-1}\right) \text {, populações (3), híbridos (2) }\end{array}$ & 10 & 38,96 & 5,50 & 0,35 & 24,90 & 53,09 \\
\hline $1998 / 1999$ & Guarapuava & 1 & $\begin{array}{l}\text { Doses N-ureia }(0,50,100,150 \mathrm{e} \\
\left.200 \mathrm{~kg} \mathrm{ha}^{-1}\right) \text {, pré-culturas }(2)\end{array}$ & 11 & 42,08 & 5,40 & 0,40 & 14,80 & 54,33 \\
\hline $1999 / 2000$ & Guarapuava & 1 & $\begin{array}{l}\text { Doses N-ureia }(0,50,100,150 \text { e } \\
\left.200 \mathrm{~kg} \mathrm{ha}^{-1}\right) \text {, pré-culturas }(2)\end{array}$ & 12 & 28,25 & 5,20 & 0,42 & 14,50 & 68,96 \\
\hline \multirow[t]{4}{*}{$2000 / 2001$} & Guarapuava & 4 & $\begin{array}{l}\text { Doses N-ureia }(0,50,100,150 \text { e } \\
\left.200 \mathrm{~kg} \mathrm{ha}^{-1}\right) \text {, pré-culturas }(2)\end{array}$ & 13 & 22,48 & 5,20 & 0,36 & 8,69 & 49,24 \\
\hline & & & $\begin{array}{l}\text { Doses N-ureia }(0,50,100,150 \text { e } \\
\left.200 \mathrm{~kg} \mathrm{ha}^{-1}\right) \text {, fontes N (U, NA e SA) }\end{array}$ & 13 & 22,48 & 5,20 & 0,36 & 8,69 & 49,24 \\
\hline & & & $\begin{array}{l}\text { Doses N-ureia }(0,50,100,150 \mathrm{e} \\
\left.200 \mathrm{~kg} \mathrm{ha}^{-1}\right) \text {, épocas aplicação N (2) }\end{array}$ & 13 & 22,48 & 5,20 & 0,36 & 8,69 & 49,24 \\
\hline & & & $\begin{array}{l}\text { Doses N-ureia }(0,50,100,150 \mathrm{e} \\
\left.200 \mathrm{~kg} \mathrm{ha}^{-1}\right) \text {, populações }(4)\end{array}$ & 13 & 22,48 & 5,20 & 0,36 & 8,69 & 49,24 \\
\hline \multirow[t]{4}{*}{$2001 / 2002$} & Guarapuava & 4 & $\begin{array}{l}\text { Doses N-ureia }(0,50,100,150 \text { e } \\
\left.200 \mathrm{~kg} \mathrm{ha}^{-1}\right) \text {, pré-culturas (6) }\end{array}$ & 14 & 31,09 & 5,00 & 0,48 & 19,20 & 53,99 \\
\hline & & & $\begin{array}{l}\text { Doses N-ureia }(0,50,100,150 \text { e } \\
\left.200 \mathrm{~kg} \mathrm{ha}^{-1}\right) \text {, fontes N (U, NA e SA) }\end{array}$ & 14 & 31,09 & 5,00 & 0,48 & 19,20 & 53,99 \\
\hline & & & $\begin{array}{l}\text { Doses N-ureia }(0,50,100,150 \mathrm{e} \\
\left.200 \mathrm{~kg} \mathrm{ha}^{-1}\right) \text {, épocas aplicação N (2) }\end{array}$ & 14 & 31,09 & 5,00 & 0,48 & 19,20 & 53,99 \\
\hline & & & $\begin{array}{l}\text { Doses N-ureia }(0,50,100,150 \mathrm{e} \\
\left.200 \mathrm{~kg} \mathrm{ha}^{-1}\right) \text {, populações }(4)\end{array}$ & 14 & 31,09 & 5,00 & 0,48 & 19,20 & 53,99 \\
\hline \multirow[t]{4}{*}{$2002 / 2003$} & Guarapuava & 4 & $\begin{array}{l}\text { Doses N-ureia }(0,50,100,150 \text { e } \\
\left.200 \mathrm{~kg} \mathrm{ha}^{-1}\right) \text {, pré-culturas }(6)\end{array}$ & 15 & 33,02 & 4,75 & 0,44 & 23,90 & 46,48 \\
\hline & & & $\begin{array}{l}\text { Doses N-ureia }(0,50,100,150 \text { e } \\
\left.200 \mathrm{~kg} \mathrm{ha}^{-1}\right) \text {, fontes N (U, NA e SA) }\end{array}$ & 15 & 31,95 & 4,80 & 0,45 & 20,80 & 47,71 \\
\hline & & & $\begin{array}{l}\text { Doses N-ureia }(0,50,100,150 \mathrm{e} \\
\left.200 \mathrm{~kg} \mathrm{ha}^{-1}\right) \text {, épocas aplicação N (2) }\end{array}$ & 15 & 31,95 & 4,80 & 0,45 & 20,80 & 47,71 \\
\hline & & & $\begin{array}{l}\text { Doses N-ureia }(0,50,100,150 \mathrm{e} \\
\left.200 \mathrm{~kg} \mathrm{ha}^{-1}\right) \text {, populações }(4)\end{array}$ & 15 & 31,95 & 4,80 & 0,45 & 20,80 & 47,71 \\
\hline \multirow[t]{4}{*}{$2003 / 2004$} & Guarapuava & 4 & $\begin{array}{l}\text { Doses N-ureia }(0,50,100,150 \text { e } \\
\left.200 \mathrm{~kg} \mathrm{ha}^{-1}\right) \text {, pré-culturas (2) }\end{array}$ & 16 & 42,15 & 4,60 & 0,48 & 16,50 & 40,49 \\
\hline & & & $\begin{array}{l}\text { Doses N-ureia }(0,50,100,150 \text { e } \\
\left.200 \mathrm{~kg} \mathrm{ha}^{-1}\right) \text {, fontes N (U, NA e SA) }\end{array}$ & 16 & 42,15 & 4,60 & 0,48 & 16,50 & 40,49 \\
\hline & & & $\begin{array}{l}\text { Doses N-ureia }(0,50,100,150 \mathrm{e} \\
\left.200 \mathrm{~kg} \mathrm{ha}^{-1}\right) \text {, épocas aplicação N (2) }\end{array}$ & 16 & 42,15 & 4,60 & 0,48 & 16,50 & 40,49 \\
\hline & & & $\begin{array}{l}\text { Doses N-ureia }(0,50,100,150 \text { e } \\
\left.200 \mathrm{~kg} \mathrm{ha}^{-1}\right) \text {, populações (4) }\end{array}$ & 16 & 42,15 & 4,60 & 0,48 & 16,50 & 40,49 \\
\hline \multirow[t]{9}{*}{$2004 / 2005$} & Guarapuava & 7 & $\begin{array}{l}\text { Doses N-ureia }(0,50,100,150 \text { e } \\
\left.200 \mathrm{~kg} \mathrm{ha}^{-1}\right) \text {, fontes N (U, NA e SA) }\end{array}$ & 17 & 35,06 & 4,80 & 0,44 & 16,00 & 54,00 \\
\hline & & & $\begin{array}{l}\text { Doses N-ureia }(0,50,100,150 \mathrm{e} \\
\left.200 \mathrm{~kg} \mathrm{ha}^{-1}\right) \text {, épocas aplicação N (3) }\end{array}$ & 17 & 33,12 & 4,80 & 0,51 & 12,90 & 52,72 \\
\hline & & & $\begin{array}{l}\text { Doses N-ureia }(0,50,100,150 \mathrm{e} \\
\left.200 \mathrm{~kg} \mathrm{ha}^{-1}\right) \text {, populações }(4)\end{array}$ & 17 & 33,12 & 4,80 & 0,51 & 12,90 & 52,72 \\
\hline & & & $\begin{array}{l}\text { Doses N-ureia }(0,100,150,200 \text { e } \\
\left.250 \mathrm{~kg} \mathrm{ha}^{-1}\right) \text {, pré-culturas (6) }\end{array}$ & 17 & 33,12 & 4,80 & 0,51 & 12,90 & 52,72 \\
\hline & & & $\begin{array}{l}\text { Doses N-ureia base }(0,20,40,60 \text { e } \\
\left.80 \mathrm{~kg} \mathrm{ha}^{-1}\right) \text {, dose N-ureia cobertura } \\
\left(0,100,120,140,160 \text { e } 180 \mathrm{~kg} \mathrm{ha}^{-1}\right) \\
\text { pré-culturas }(2)\end{array}$ & 17 & 31,36 & 4,80 & 0,44 & 17,30 & 52,37 \\
\hline & & & $\begin{array}{l}\left.\text { Doses N-ureia (0, 100, e } 200 \mathrm{~kg} \mathrm{ha}^{-1}\right) \text {, } \\
\text { híbridos (8) }\end{array}$ & 17 & 30,39 & 5,10 & 0,40 & 17,90 & 57,39 \\
\hline & & & $\begin{array}{l}\text { Doses } \mathrm{N} \text { florescimento }(0,50,100 \mathrm{e} \\
\left.150 \mathrm{~kg} \mathrm{ha}^{-1}\right) \text {, fontes N (U, NA e SA) }\end{array}$ & 17 & 33,12 & 4,80 & 0,51 & 12,90 & 52,72 \\
\hline & Pinhão & 1 & $\begin{array}{l}\text { Doses N-ureia }(0,50,100,150 \text { e } \\
\left.200 \mathrm{~kg} \mathrm{ha}^{-1}\right) \text {, fontes N (U, NA e SA) }\end{array}$ & 17 & 42,44 & 4,40 & 0,54 & 8,15 & 41,20 \\
\hline & Candói & 1 & $\begin{array}{l}\text { Doses N-ureia }(0,50,100,150 \text { e } \\
\left.200 \mathrm{~kg} \mathrm{ha}^{-1}\right) \text {, fontes N (U, NA e SA) }\end{array}$ & 17 & 53,48 & 5,05 & 0,32 & 4,55 & 61,50 \\
\hline
\end{tabular}




\section{Quadro 1. Continuação}

\begin{tabular}{|c|c|c|c|c|c|c|c|c|c|}
\hline \multirow{2}{*}{$\begin{array}{c}\text { Ano } \\
\text { agrícola }\end{array}$} & \multirow{2}{*}{ Local } & \multicolumn{2}{|r|}{ Experimentos } & \multirow{2}{*}{$\begin{array}{c}\text { Anos } \\
\text { em PD }\end{array}$} & \multicolumn{5}{|c|}{ Características de fertilidade do solo } \\
\hline & & $\mathbf{N}^{\circ}$ & Fatores e Níveis & & $\mathbf{C}$ & $\mathrm{pH}_{\mathrm{CaCl}_{2}}$ & $\mathbf{K}$ & $\mathbf{P}$ & $\mathbf{V}$ \\
\hline & & & & & $\mathrm{g} \mathrm{kg}^{-1}$ & & $\mathrm{cmol}_{\mathrm{C}} \mathrm{dm}^{-3}$ & $\mathrm{mg} \mathrm{dm} \mathrm{m}^{-3}$ & $\%$ \\
\hline \multirow[t]{14}{*}{$2005 / 2006$} & Guarapuava & 10 & $\begin{array}{l}\text { Doses N-ureia }(0,50,100,150 \text { e } \\
\left.200 \mathrm{~kg} \mathrm{ha}^{-1}\right) \text {, fontes } \mathrm{N}(\mathrm{U}, \mathrm{NA} \text { e SA) }\end{array}$ & 18 & 30,10 & 5,00 & 0,26 & 17,40 & 39,65 \\
\hline & & & $\begin{array}{l}\text { Doses N-ureia }(0,50,100,150 \text { e } \\
\left.200 \mathrm{~kg} \mathrm{ha}^{-1}\right) \text {, épocas aplicação N (3) }\end{array}$ & 18 & 30,10 & 5,00 & 0,26 & 17,40 & 39,65 \\
\hline & & & Doses N-ureia $(0,50,100,150 \mathrm{e}$ & 18 & 30,10 & 5,00 & 0,26 & 17,40 & 39,65 \\
\hline & & & $\begin{array}{l}\text { Doses N-ureia }(0,100,150,200 \\
\left.\text { e } 250 \mathrm{~kg} \mathrm{ha}^{-1}\right) \text {, pré-culturas }(6)\end{array}$ & 18 & 30,10 & 5,00 & 0,26 & 17,40 & 39,65 \\
\hline & & & $\begin{array}{l}\text { Pré-culturas (aveia branca, aveia preta, } \\
\text { ervilhaca comum, nabo forrageiro e } \\
\text { consórcio aveia branca/ervilhaca comum } \\
(1 / 3+2 / 3) \text {, produção de biomassa (3) }\end{array}$ & 18 & 30,10 & 5,00 & 0,26 & 17,40 & 39,65 \\
\hline & & & $\begin{array}{l}\text { Faixas sem N para avaliar fornecimento } \\
\text { de } \mathrm{N} \text { do solo }\end{array}$ & 18 & 38,95 & 4,70 & 0,56 & 13,00 & 45,00 \\
\hline & & & $\begin{array}{l}\text { Doses N-ureia }\left(0,100 \text {, e } 200 \mathrm{~kg} \mathrm{ha}^{-1}\right) \text {, } \\
\text { híbridos (8) }\end{array}$ & 18 & 46,05 & 5,10 & 0,34 & 19,60 & 49,15 \\
\hline & & & $\begin{array}{l}\text { Doses N florescimento }(0,50,100 \text { e } \\
\left.150 \mathrm{~kg} \mathrm{ha}^{-1}\right) \text {, fontes N (U, NA e SA) }\end{array}$ & 18 & 30,10 & 5,00 & 0,26 & 17,40 & 39,65 \\
\hline & & & $\begin{array}{l}\text { Doses } \mathrm{N}\left(0,75,150 \text { e } 225 \mathrm{~kg} \mathrm{ha}^{-1} \mathrm{~N}\right) \\
\text { fontes } \mathrm{N} \text {-perdas (ureia e ureia-NBPT) }\end{array}$ & 18 & 32,72 & 4,80 & 0,49 & 14,50 & 35,64 \\
\hline & Pinhão & 2 & $\begin{array}{l}\text { Doses N-ureia }(0,50,100,150 \text { e } \\
\left.200 \mathrm{~kg} \mathrm{~h}^{-1}\right) \text {, fontes N (U, NA e SA) }\end{array}$ & 30 & 45,35 & 4,20 & 0,56 & 8,50 & 25,20 \\
\hline & & & $\begin{array}{l}\text { Faixas sem } \mathrm{N} \text { para avaliar fornecimento } \\
\text { de } \mathrm{N} \text { do solo }\end{array}$ & 30 & 45,35 & 4,20 & 0,56 & 8,50 & 25,20 \\
\hline & Candói & 2 & $\begin{array}{l}\text { Doses N-ureia }(0,50, \quad 100,150 \text { e } \\
\left.200 \mathrm{~kg} \mathrm{ha}^{-1}\right) \text {, fontes N }(\mathrm{U}, \mathrm{NA} \mathrm{e} \mathrm{SA})\end{array}$ & 30 & 54,65 & 4,90 & 0,35 & 4,90 & 61,00 \\
\hline & & & $\begin{array}{l}\text { Faixas sem } \mathrm{N} \text { para avaliar fornecimento } \\
\text { de } \mathrm{N} \text { do solo }\end{array}$ & 30 & 54,65 & 4,90 & 0,35 & 4,90 & 61,00 \\
\hline & $\begin{array}{l}\text { Teixeira } \\
\text { Soares }\end{array}$ & 1 & $\begin{array}{l}\text { Faixas sem } \mathrm{N} \text { para avaliar fornecimento } \\
\text { de } \mathrm{N} \text { do solo }\end{array}$ & 25 & 24,42 & 5,40 & 0,53 & 5,80 & 68,00 \\
\hline \multirow[t]{12}{*}{$2006 / 2007$} & Guarapuava & 7 & $\begin{array}{l}\text { Doses N-ureia }(0,50,100,150 \text { e } \\
\left.200 \mathrm{~kg} \mathrm{ha}^{-1}\right) \text {, fontes N (U, NA e SA) }\end{array}$ & 19 & 48,71 & 5,00 & 0,43 & 11,50 & 57,77 \\
\hline & & & $\begin{array}{l}\text { Doses N-ureia }(0,50,100,150 \text { e } \\
\left.200 \mathrm{~kg} \mathrm{ha}^{-1}\right) \text {, épocas aplicação N (3) }\end{array}$ & 19 & 48,71 & 5,00 & 0,43 & 11,50 & 57,77 \\
\hline & & & $\begin{array}{l}\text { Doses N-ureia }(0,50,100,150 \text { e } \\
\left.200 \mathrm{~kg} \mathrm{ha}^{-1}\right) \text {, populações (4) }\end{array}$ & 19 & 48,71 & 5,00 & 0,43 & 11,50 & 57,77 \\
\hline & & & $\begin{array}{l}\text { Doses N-ureia }(0,100,150,200 \text { e } \\
\left.250 \mathrm{~kg} \mathrm{ha}^{-1}\right) \text {, pré-culturas (6) }\end{array}$ & 19 & 48,71 & 5,00 & 0,43 & 11,50 & 57,77 \\
\hline & & & $\begin{array}{l}\text { Pré -culturas (aveia branca, aveia preta, } \\
\text { ervilhaca comum, nabo forrageiro e } \\
\text { consórcio aveia branca/ervilhaca comum } \\
(1 / 3+2 / 3) \text {, produção de biomassa (3) }\end{array}$ & 19 & 48,71 & 5,00 & 0,43 & 11,50 & 57,77 \\
\hline & & & $\begin{array}{l}\text { Faixas sem } \mathrm{N} \text { para avaliar fornecimento } \\
\text { de } \mathrm{N} \text { do solo }\end{array}$ & 19 & 48,71 & 5,00 & 0,43 & 11,50 & 57,77 \\
\hline & & & $\begin{array}{l}\text { Doses } \mathrm{N}\left(0,75,150 \text { e } 225 \mathrm{~kg} \mathrm{ha}^{-1} \mathrm{~N}\right) \text {, } \\
\text { fontes } \mathrm{N} \text {-perdas (ureia e ureia-NBPT) }\end{array}$ & 19 & 48,71 & 5,00 & 0,43 & 11,50 & 57,77 \\
\hline & Pinhão & 2 & $\begin{array}{l}\text { Doses N-ureia }(0,50,100,150 \text { e } \\
\left.200 \mathrm{~kg} \mathrm{~h}^{-1}\right) \text {, fontes N (U, NA e SA) }\end{array}$ & 31 & 39,53 & 4,60 & 0,53 & 7,80 & 57,20 \\
\hline & & & $\begin{array}{l}\text { Faixas sem } \mathrm{N} \text { para avaliar fornecimento } \\
\text { de } \mathrm{N} \text { do solo }\end{array}$ & 31 & 39,53 & 4,60 & 0,53 & 7,80 & 57,20 \\
\hline & Candói & 2 & $\begin{array}{l}\text { Dose s N-ureia }(0,50,100,150 \text { e } \\
\left.200 \mathrm{~kg} \mathrm{ha}^{-1}\right) \text {, fontes N (U, NA e SA) }\end{array}$ & 31 & 52,32 & 5,20 & 0,30 & 4,20 & 62,00 \\
\hline & & & $\begin{array}{l}\text { Faixas sem N para avaliar fornecimento } \\
\text { de } \mathrm{N} \text { do solo }\end{array}$ & 31 & 52,32 & 5,20 & 0,30 & 4,20 & 62,00 \\
\hline & $\begin{array}{l}\text { Teixeira } \\
\text { Soares }\end{array}$ & 1 & $\begin{array}{l}\text { Faixas sem } \mathrm{N} \text { para avaliar fornecimento } \\
\text { de } \mathrm{N} \text { do solo }\end{array}$ & 26 & 29,07 & 5,00 & 0,51 & 6,00 & 64,00 \\
\hline \multirow[t]{3}{*}{$2007 / 2008$} & Guarapuava & 3 & $\begin{array}{l}\text { Doses N-ureia }(0,100,150,200 \text { e } \\
\left.250 \mathrm{~kg} \mathrm{ha}^{-1}\right) \text {, pré-culturas }(6)\end{array}$ & 20 & 40,19 & 5,20 & 0,47 & 12,80 & 62,45 \\
\hline & & & $\begin{array}{l}\text { Pré -culturas (aveia branca, aveia preta, } \\
\text { ervilhaca comum, nabo forrageiro e } \\
\text { consórcio aveia branca/ervilhaca comum } \\
(1 / 3+2 / 3) \text {, produção de biomassa (3) }\end{array}$ & 20 & 40,19 & 5,20 & 0,47 & 12,80 & 62,45 \\
\hline & & & $\begin{array}{l}\text { Doses } \mathrm{N}\left(0,75,150 \text { e } 225 \mathrm{~kg} \mathrm{ha}^{-1} \mathrm{~N}\right) \text {, font } \\
\mathrm{N} \text {-perdas (ureia e ureia com inibidor de }\end{array}$ & $\begin{array}{c}20 \\
\text { ase) }\end{array}$ & 40,19 & 5,20 & 0,47 & 12,80 & 62,45 \\
\hline
\end{tabular}

U: ureia, NA: nitrato de amônio, SA: sulfato de amônio. 


$$
\begin{gathered}
\mathrm{N} \text { milho }=\mathrm{N} \text { solo }+\mathrm{N} \text { planta de } \\
\text { cobertura }+\mathrm{N} \text { adubo }
\end{gathered}
$$

Com base na equação (1), avaliaram-se quatro aspectos fundamentais para embasar a indicação de $\mathrm{N}$ : (a) qual a demanda de $\mathrm{N}$ pelo milho para diferentes faixas de rendimento de grãos; (b) qual o potencial do solo em fornecer $\mathrm{N}$ para o milho; (c) qual o efeito das plantas de cobertura de inverno na disponibilidade de N para o milho, e (d) qual a eficiência do fertilizante nitrogenado aplicado.

\section{Demanda de $\mathrm{N}$ pelo milho para diferentes expectativas de rendimento de grãos}

A quantidade de $\mathrm{N}$ que o milho necessita absorver varia com a faixa de rendimento da cultura, sendo uma informação básica quando se visa o desenvolvimento de um sistema de indicação de N. Para obter essa informação, a relação entre a quantidade de $\mathrm{N}$ absorvido e o rendimento de grãos de milho foi avaliada em 21 experimentos, com diferentes combinações de doses de $\mathrm{N}$ (0 a $250 \mathrm{~kg} \mathrm{ha}^{-1}$ ), adubos nitrogenados (ureia, sulfato de amônio e nitrato de amônio), locais (Guarapuava, Candói, Pinhão e Teixeira Soares) e diferentes anos agrícolas (2005/2006 e 2006/2007) (Quadro 1).

\section{Fornecimento de $\mathrm{N}$ pelo solo para o milho}

$\mathrm{O}$ solo fornece $\mathrm{N}$ para as culturas a partir da mineralização do $\mathrm{N}$ da MO. De forma simplificada, considera-se que quanto maior o teor de MO do solo, maior será a quantidade de $\mathrm{N}$ disponível para o milho. Objetivando avaliar a capacidade de suprimento de $\mathrm{N}$ pelos solos da região, realizou-se um total de oito experimentos (Quadro 1), visando estimar a taxa de mineralização aparente do $\mathrm{N}$ da $\mathrm{MO}$ do solo. Os experimentos foram realizados em quatro locais e por dois anos, para contemplar variações no tipo de solo e de condições climáticas.

Os experimentos consistiram no cultivo de milho em solo descoberto, cujos resíduos vegetais da cultura de inverno foram totalmente removidos, e sem o emprego de adubação nitrogenada, ou seja, a única fonte de $\mathrm{N}$ para o milho foi o $\mathrm{N}$ mineralizado da $\mathrm{MO}$ do solo. Apenas realizou-se adubação com P e K, conforme a indicação para a cultura. O estoque de $\mathrm{N}$ total do solo foi calculado a partir da concentração de $\mathrm{N}$ e da densidade do solo na camada de $0-10 \mathrm{~cm}$, e com base na quantidade de $\mathrm{N}$ absorvida pelo milho, estimou-se a taxa de mineralização aparente do N (\%) da MO do solo a partir da equação (2):

$\underset{\text { Taxa de mineralização }}{\text { aparente do } \mathrm{N}}=\left[\frac{\mathrm{N} \text { na biomassa do milho }}{\text { Estoque de } \mathrm{N} \text { do solo }(0-10 \mathrm{~cm})}\right] \times 100$

Efeito das plantas de cobertura na disponibilidade de $\mathbf{N}$ para $\mathrm{o}$ milho

O efeito das plantas de cobertura de inverno na disponibilidade de $\mathrm{N}$ foi avaliado em 14 experimentos
(1998/1999 a 2007/2008, Quadro 1) de duas formas. O efeito das gramíneas foi avaliado pela comparação da quantidade de $\mathrm{N}$ absorvido pelo milho quando cultivado sobre pousio e quando cultivado em sucessão ao trigo (Triticum aestivum L.), à cevada (Hordeum vulgare L.), à aveia branca (Avena sativa L.) e à aveia preta (Avena strigosa S.). Por sua vez, o papel das leguminosas [ervilhaca comum (Vicia sativa L.), ervilhaca peluda (Vicia villosa R.), ervilha-forrageira (Pisum sativum L.) e serradela (Ornothopus sativus Brot.)], do nabo forrageiro (Raphanus raphanistrum L.) e do consórcio gramínea-leguminosa (1/3 aveia branca e $2 / 3$ ervilhaca peluda), no fornecimento de $\mathrm{N}$ para o milho foi avaliado a partir da equivalência em $\mathrm{N}$ mineral comparado ao milho cultivado em sucessão a gramíneas (Bayer et al., 1998; Spagnollo et al., 2001).

\section{Eficiência aparente do fertilizante nitrogenado e dose de $\mathrm{N}$ a ser aplicada no milho}

A partir da diferença entre a demanda de $\mathrm{N}$ e as quantidades fornecidas pelo solo e plantas de cobertura, estimou-se a quantidade de $\mathrm{N}$ a ser aplicada na adubação (Equação 3), a qual levou em consideração também a eficiência do $\mathrm{N}$ aplicado em cobertura. A estimativa da eficiência aparente do fertilizante nitrogenado foi realizada segundo a equação (4).

$$
\begin{gathered}
\mathrm{N} \text { adubo }=\left[\frac{\mathrm{N} \text { necessário milho }-\mathrm{N} \text { solo }-\mathrm{N} \text { planta cobertura }}{\text { Efíciência do } \mathrm{N} \text { mineral }}\right] \\
\underset{\mathrm{N} \text { mineral }}{\text { Eficiencia do }}=\left[\frac{\mathrm{N} \text { absorvido com adubação } \mathrm{N}-\mathrm{N} \text { aborvido sem adubação } \mathrm{N}}{\text { Dose de } \mathrm{N}}\right]
\end{gathered}
$$

A eficiência aparente do $\mathrm{N}$ aplicado via adubo mineral foi avaliada em 27 experimentos, constituídos por doses de $\mathrm{N}$ em cobertura no milho, diferentes plantas de cobertura, híbridos, populações de plantas, locais e anos agrícolas (Quadro 1).

\section{Validação do sistema de indicação de $\mathrm{N}$ para milho}

Dois procedimentos foram utilizados para validar as quantidades de $\mathrm{N}$ indicadas para a cultura do milho. O primeiro procedimento consistiu na comparação das quantidades indicadas com as doses de máxima eficiência econômica (DMEE) calculadas para 20 diferentes situações de teor de MO do solo, planta de cobertura e faixa de rendimento. $\mathrm{O}$ segundo procedimento consistiu na comparação das quantidades de $\mathrm{N}$ indicadas para a região centro-sul do PR, obtidas no presente estudo, com as quantidades de $\mathrm{N}$ indicadas para os Estados do RS/SC (Amado et al., 2002; Comissão... 2004) para condições similares de teor de MO do solo, planta de cobertura e faixa de rendimento de milho. Em ambos procedimentos, regressões lineares foram ajustadas e a relação entre as variáveis foi avaliada pela significância do coeficiente de regressão linear. 


\section{RESULTADOS E DISCUSSÃO}

\section{Demanda de $\mathrm{N}$ pelo milho para diferentes faixas de rendimento de grãos}

A quantidade de $\mathrm{N}$ absorvida pelo milho variou de 70 a $205 \mathrm{~kg} \mathrm{ha}^{-1}$, a qual aumentou de forma não linear com o aumento da faixa de rendimento da cultura (Figura 2a). Verifica-se que, para produzir entre $6 \mathrm{e}$ $8 \mathrm{t} \mathrm{ha}^{-1}$ de grãos, foi necessário acumular em média $70 \mathrm{~kg} \mathrm{ha}^{-1}$ de N na matéria seca da parte aérea da cultura. Entretanto, em comparação à faixa de rendimento entre 6 e $8 \mathrm{t} \mathrm{ha}^{-1}$, a quantidade de $\mathrm{N}$ absorvida pelo milho aumentou em $35 \mathrm{~kg} \mathrm{ha}^{-1}$ para rendimentos entre 8,1 e $10 \mathrm{t} \mathrm{ha}^{-1}$, em $80 \mathrm{~kg} \mathrm{ha}^{-1}$ para rendimentos entre 10,1 e $12 \mathrm{t} \mathrm{ha}^{-1} \mathrm{e}$, em $130 \mathrm{~kg} \mathrm{ha}^{-1}$ para rendimentos entre $12,1 \mathrm{e} 14 \mathrm{t} \mathrm{ha}^{-1}$, ou seja, para cada aumento de $2 \mathrm{t} \mathrm{ha}^{-1}$ na faixa de rendimento ocorreu um aumento não linear (35, 45 e $\left.50 \mathrm{~kg} \mathrm{ha}^{-1}\right)$ na quantidade de $\mathrm{N}$ absorvida pelo milho (Figura 2a).

Esse aumento não linear na necessidade de $\mathrm{N}$ devese à fisiologia da cultura pela qual ocorre diminuição da eficiência das plantas em converter o $\mathrm{N}$ absorvido em grãos à medida que aumenta a faixa de rendimento (Fernandes, 1998). Na figura $2 b$ é apresentada essa diminuição exponencial da eficiência do $\mathrm{N}$ absorvido $(p<0,0034)$, expressa pela quantidade de grão produzido para cada unidade de $\mathrm{N}$ aplicado, com o aumento da faixa de rendimento da cultura. Esses resultados são semelhantes aos obtidos por Fernandes (1998), e refletem o aumento não linear da dose de N para o aumento da faixa de rendimento (Amado et al., 2002), e por essa razão, uma dose de máxima eficiência econômica deve ser almejada (Anghinoni, 1984).

\section{Suprimento de $\mathrm{N}$ pelo solo para o milho}

Nos experimentos em que os resíduos culturais foram removidos e não foi realizada adubação nitrogenada, a quantidade de $\mathrm{N}$ absorvida pelo milho teve uma relação direta com os teores de $\mathrm{MO}$ do solo (Figura 3a), indicando a adequação de seu uso como um indicador de disponibilidade de $\mathrm{N}$ do solo (Anghinoni, 1984; Bayer \& Fontoura, 2006). O grau de significância moderado $(p<0,11)$ dessa relação deve estar na variação da taxa de decomposição da $\mathrm{MO}$ em função dos diferentes teores de argila dos solos e condições climáticas (Bayer, 1996; Mielniczuk et al., 2003).

A partir dos estoques de $\mathrm{N}$ no solo $(0-10 \mathrm{~cm})$ e da quantidade de $\mathrm{N}$ absorvido pelo milho sem aplicação de fertilizante nitrogenado e em solo descoberto (sem palhada da cultura antecessora), calculou-se a taxa de mineralização aparente do N da MO (Equação 2) de quatro solos de diferentes localidades (Quadro 1; Figura 3b). Na média de dois anos, a taxa de mineralização aparente do $\mathrm{N}$ da $\mathrm{MO}$ nos diferentes solos variou de 3,1 a 5,2 \% (Figura 5). Com base nesses resultados e por ser uma variável dependente do tipo de solo (textura, $\mathrm{pH}$, etc.) e das condições climáticas, definiu-se como adequada a utilização de uma taxa de $3 \%$ de mineralização do $\mathrm{N}$ da $\mathrm{MO}$ do solo.

Essa taxa de mineralização aparente foi aplicada para o cálculo da quantidade de $\mathrm{N}$ fornecida pelo solo ao milho em solos com diferentes teores de MO. Nesse sentido, com base no banco de dados referente às análises de solo da região (Fontoura et al., 2004), os solos foram divididos em três classes de teores de MO (Figura 4). A partir da taxa de mineralização de $3 \%$ do $\mathrm{N}$ presente na $\mathrm{MO}$ e dos teores de 30,50 e $70 \mathrm{~g} \mathrm{~kg}^{-1}$ de MO, respectivamente, para as classes $<40,41-60$ e $>60 \mathrm{~g} \mathrm{~kg}^{-1}$ de MO (Figura 4), estimou-se que os solos da região nessas diferentes classes de teores de MO teriam capacidade de suprir cerca de 37,62 e $87 \mathrm{~kg} \mathrm{ha}^{-1}$ de N, respectivamente, durante o período de crescimento e desenvolvimento da cultura do milho.

\section{Efeito das plantas de cobertura no suprimento} de $\mathrm{N}$ para o milho

O milho em sucessão a gramíneas (aveia branca, aveia preta, trigo e cevada) absorveu, em média, $15 \mathrm{~kg} \mathrm{ha}{ }^{-1}$ de $\mathrm{N}$ menos do que quando cultivado em área mantida sob pousio no inverno, sugerindo a
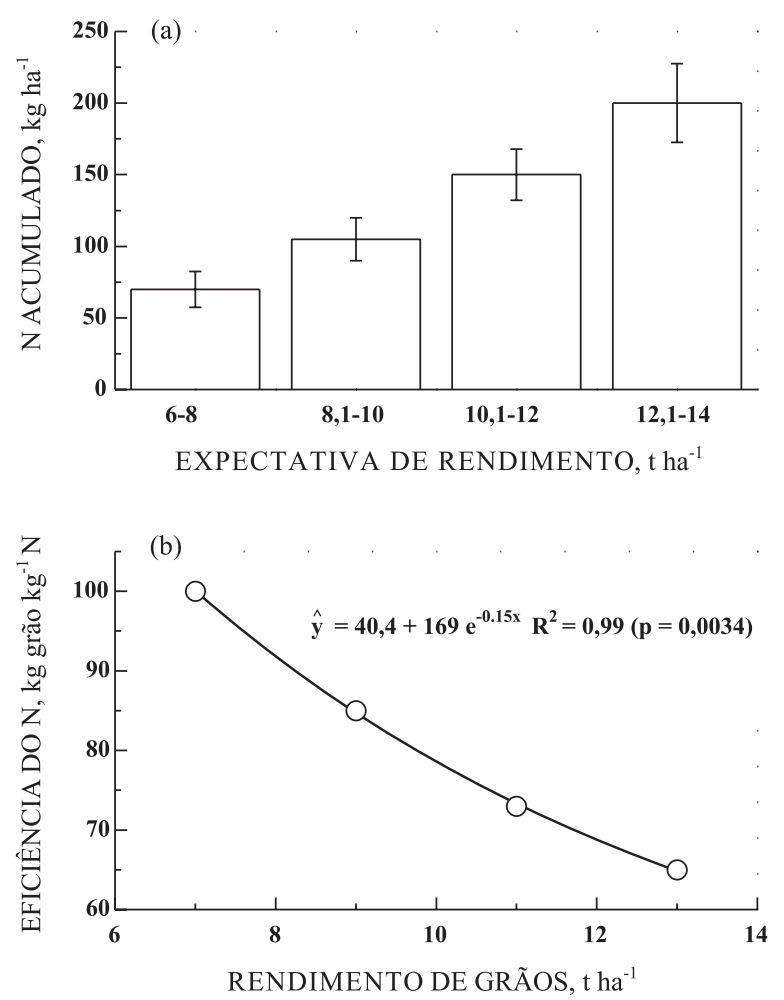

Figura 2. Quantidades de $\mathrm{N}$ acumulado na matéria seca do milho em diferentes faixas de rendimento de grãos da cultura (a) e eficiência do $\mathrm{N}$ absorvido (produção de grãos por $\mathrm{kg}$ de $\mathrm{N}$ absorvido) (b). 

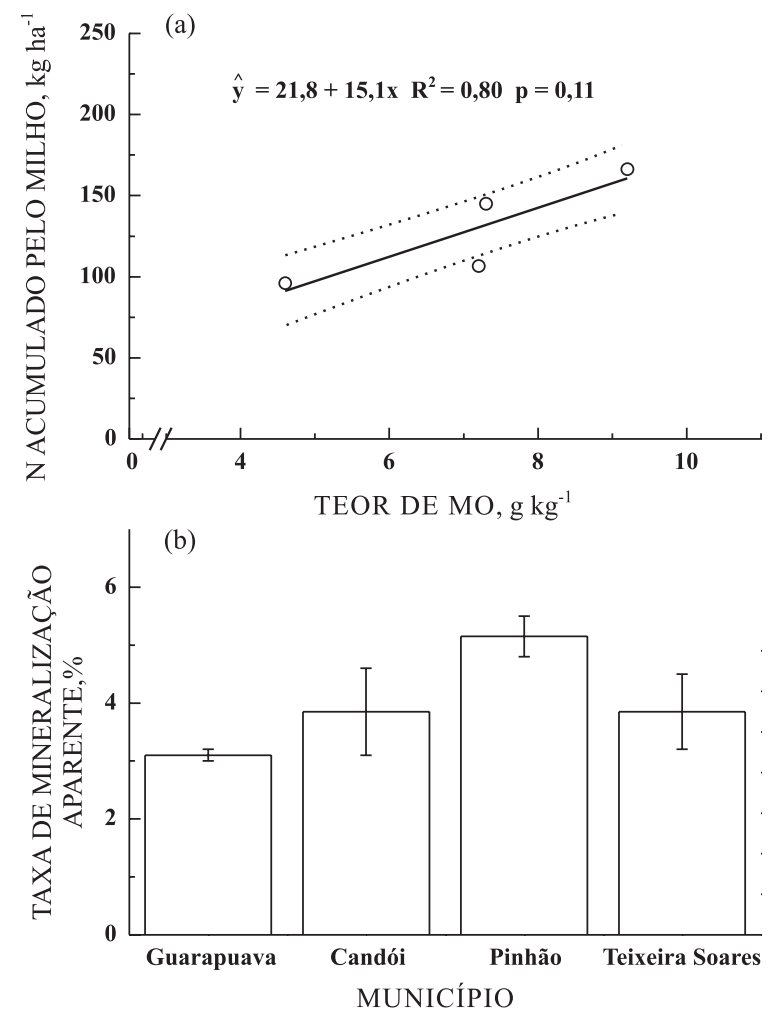

Figura 3. Relação entre o teor de matéria orgânica (MO, 0-10 cm) do solo e a quantidade de $\mathrm{N}$ acumulado pelo milho (a) e taxas de mineralização aparente do N da MO (b) estimadas para quatro diferentes locais. As linhas tracejadas representam o intervalo de confiança $90 \%$ da equação ajustada.

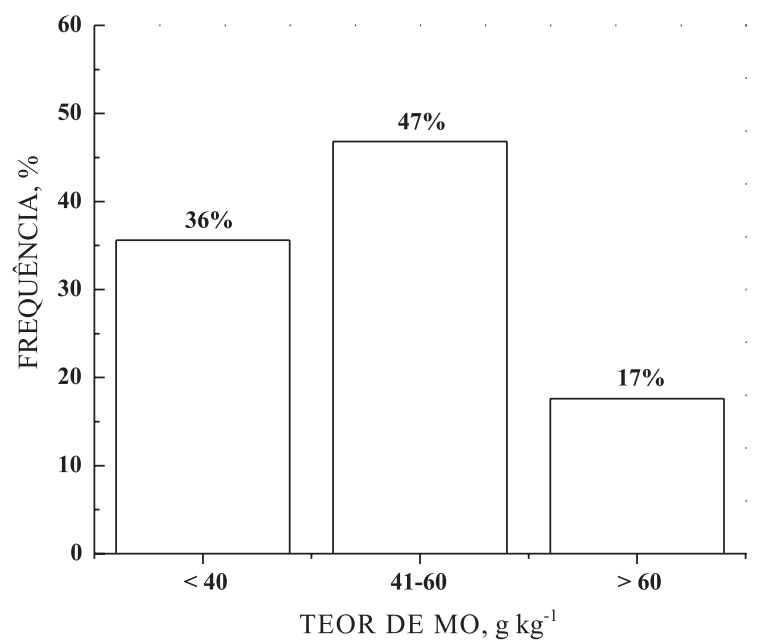

Figura 4. Frequência de ocorrência do teor de MO na camada de 0-10 cm, na região centro-sul do PR (3.800 amostras).

ocorrência de imobilização líquida de $\mathrm{N}$ quando da decomposição da palhada de gramíneas com alta relação C/N (Amado et al., 2000; Aita et al., 2004).
Por sua vez, o nabo forrageiro, o consórcio gramínea-leguminosa e a ervilhaca resultaram em aumento no suprimento de $\mathrm{N}$ em comparação aos sistemas com gramíneas (Figura 5a), o qual foi equivalente à aplicação de $40 \mathrm{~kg} \mathrm{ha}^{-1}$ de $\mathrm{N}$ para o nabo forrageiro e o consórcio gramínea-leguminosa, e de $90 \mathrm{~kg} \mathrm{ha}^{-1}$ de N para a leguminosa isolada (Figura 5b). Destaca-se que, em todos os experimentos, as préculturas apresentaram alta produção de biomassa, caracterizadas por quantidades na faixa de 4 a $5 \mathrm{t} \mathrm{ha}^{-1}$ de MS. Essa característica de alta produção de biomassa pelas culturas de inverno repete-se nas lavouras comerciais da região.

A imobilização de $\mathrm{N}$ pós-gramíneas tem sido observada por diversos autores, cuja quantidade imobilizada e efeito depressivo no rendimento do milho são variáveis com a produção de biomassa das gramíneas (Aita et al., 1994; Amado et al., 1999) e reflete na indicação de maiores doses de $\mathrm{N}$ para o milho em comparação a áreas cujo cultivo ocorre em sucessão ao pousio (Amado et al., 2002). O papel das leguminosas, do consórcio gramínea-leguminosa e, mais recentemente, do nabo forrageiro em fornecer $\mathrm{N}$ para o milho tem sido bem caracterizado na
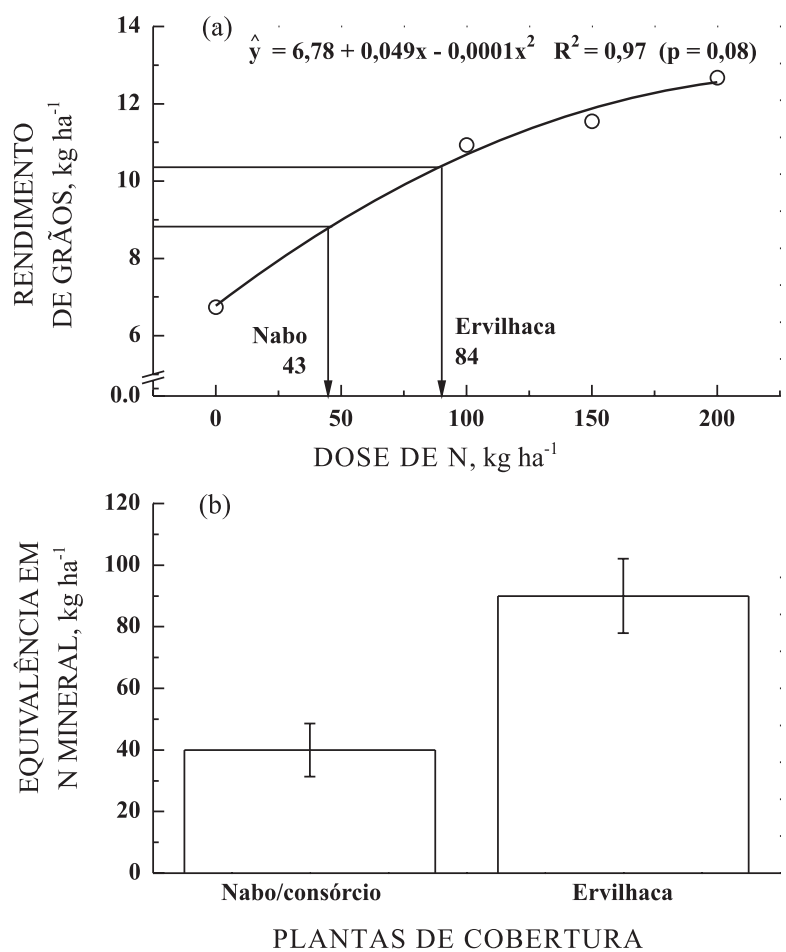

Figura 5. Efeito das plantas de cobertura de inverno na disponibilidade de $\mathrm{N}$ ao milho, sendo apresentada a forma pela qual foi estimada a equivalência em $\mathrm{N}$ mineral para os sistemas com nabo forrageiro, consórcio gramínea-leguminosa e ervilhaca isolada (a), e os valores médios de equivalência em $\mathrm{N}$ mineral dessas pré-culturas (b). 
literatura. Os valores de equivalência em $\mathrm{N}$ mineral obtidos neste estudo (40 kg ha-1 com nabo forrageiro e consórcio e $90 \mathrm{~kg} \mathrm{ha}^{-1}$ para leguminosa isolada) são muito similares aos 39 e $90 \mathrm{~kg} \mathrm{ha}^{-1}$, respectivamente, de equivalência em $\mathrm{N}$ mineral estimados em Argissolo no Rio Grande do Sul (Bayer et al., 1998), bem como à contribuição atribuída às plantas de cobertura de inverno na indicação de $\mathrm{N}$ para o milho nos estados do RS e SC (Amado et al., 2002; Comissão... 2004). Nesses Estados, a equivalência em N mineral atribuída à leguminosas com alta produção de biomassa varia entre 60 e $80 \mathrm{~kg} \mathrm{ha}^{-1}$; para nabo forrageiro e consórcio com predomínio de leguminosa, essas contribuições correspondem a aproximadamente 40 e $60 \mathrm{~kg} \mathrm{ha}^{-1}$, respectivamente (Amado et al., 2002). Portanto, considerando situações de alta produção de biomassa, a contribuição atribuída neste estudo a leguminosas, consórcio e nabo forrageiro é bastante similar à utilizada na indicação de $\mathrm{N}$ para milho nos estados do RS e SC.

\section{Eficiência aparente do fertilizante nitrogenado e dose de $\mathrm{N}$ a ser aplicada no milho}

Nos experimentos desenvolvidos em Guarapuava, Candói e Pinhão, estimou-se que a eficiência aparente média do $\mathrm{N}$ mineral aplicado em cobertura na forma de ureia foi de aproximadamente $60 \%$ (Figura 6). Esse valor de eficiência de $\mathrm{N}$ encontra-se numa faixa intermediária aos valores de 50 e 70 \% estimados por Stanford (1973), e é suportado pela baixa volatilização de amônia da ureia (13\%) na primavera-verão chuvosa da região (Fontoura \& Bayer, 2008). Além disso, outros autores têm referenciado valores de $60-65 \%$ de eficiência (Parr, 1973; Carter et al., 1976), enquanto em Argissolo do RS foi estimada eficiência de

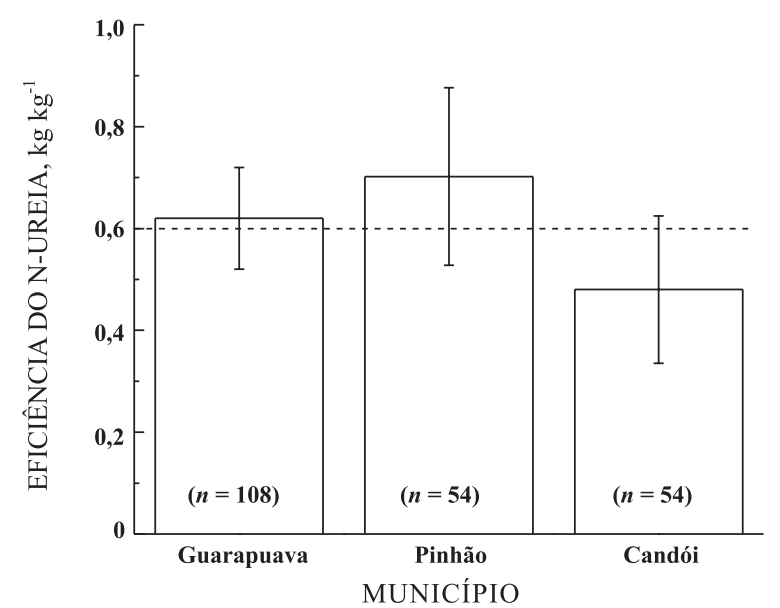

Figura 6. Eficiência do $\mathrm{N}$ aplicado em cobertura na forma de uréia ( $\mathrm{N}$ absorvido por $\mathrm{N}$ aplicado). As barras verticais representam o intervalo de confiança estimado com o erro-padrão da média calculado a partir dos resultados da eficiência do $\mathrm{N}$ calculada em $n$ tratamentos. aproximadamente $50 \%$ do $\mathrm{N}$ aplicado na forma de ureia (Freitas et al., 1996; Bayer et al., 1997).

\section{Doses de $\mathrm{N}$ para alto rendimento de milho na região centro-sul do Paraná}

A indicação de $\mathrm{N}$ foi elaborada visando a obtenção de elevados rendimentos de grãos (Quadro 2), o que é coerente com as condições climáticas regionais favoráveis ao manejo de solo e de culturas adotado pela grande maioria dos agricultores da região. Entretanto, salienta-se que a faixa de maior expectativa derendimento (12,1-14 tha-1) deve ser restrita a situações nas quais as demais condições de fertilidade do solo e de manejo da cultura estejam otimizadas, e o volume de chuva seja igual ou superior ao volume mensal histórico no período de desenvolvimento da cultura $(178 \mathrm{~mm})$. Dentre os critérios a serem observados para a definição da dose de fertilizante nitrogenado, foram consideradas três faixas de MO no solo $(<40$, $41-60$ e $\left.>60 \mathrm{~g} \mathrm{~kg}^{-1}\right)$ referentes à camada de $0-10 \mathrm{~cm}$ e três alternativas de culturas antecessoras (gramíneas, leguminosas, consórcio gramínealeguminosa e nabo forrageiro).

As quantidades de $\mathrm{N}$ demandadas pela cultura do milho, em contraste com o suprimento de $\mathrm{N}$ resultante das diferentes combinações das variáveis MO e précultura, resultaram em doses de $\mathrm{N}$ variando de $\leq 40 \mathrm{a}$ $300 \mathrm{~kg} \mathrm{ha}^{-1}$ de N. Destaca-se, a título de exemplo, que, para a obtenção de rendimentos de milho entre 12,1 e $14 \mathrm{t} \mathrm{ha}^{-1}$, as doses de $\mathrm{N}$ podem variar de $130 \mathrm{a}$ $300 \mathrm{~kg} \mathrm{ha}^{-1}$ em função dos teores de MO do solo e da cultura antecessora. Num solo com teor de MO na faixa média (41-60 $\mathrm{g} \mathrm{kg}^{-1}$ ), a dose de $\mathrm{N}$ indicada é de $260 \mathrm{~kg} \mathrm{ha}^{-1}$ após plantio de gramíneas, $210 \mathrm{~kg} \mathrm{ha}^{-1}$ quanto em sucessão a um consórcio gramínealeguminosa ou nabo forrageiro, e de $160 \mathrm{~kg} \mathrm{ha}^{-1}$ posterior ao plantio de leguminosas com alta produção de matéria seca.

Essa indicação é válida para as situações nas quais as culturas de inverno apresentam uma alta produção de biomassa, o que, normalmente, ocorre na grande maioria das propriedades da região devido ao manejo de solo e de culturas adequado. Em situações em que a pré-cultura gramínea apresentar baixa produção de matéria seca $\left(<2 \mathrm{t} \mathrm{ha}^{-1}\right)$, deve-se aplicar uma dose de $\mathrm{N} 20 \mathrm{~kg} \mathrm{ha}^{-1}$ menor do que a indicada no quadro 2 . Por sua vez, em situações em que pré-culturas gramínea-leguminosa em consórcio ou nabo forrageiro e leguminosa isolada apresentarem baixa produção de matéria seca, aplicar uma dose de $\mathrm{N}$ de 20 ou $40 \mathrm{~kg} \mathrm{ha}^{-1}$ maior, respectivamente (veja nota de rodapé do Quadro 2).

\section{Validação do sistema de indicação de $\mathrm{N}$ para milho}

Na figura 7 a, verifica-se o bom ajuste $\left(R^{2}=0,74\right.$, $p=0,03$ ) entre e o rendimento de milho obtido em 
experimentos conduzidos ao longo dos 13 anos de pesquisa de $\mathrm{N}$ em milho (Quadro 2) e as doses de máxima eficiência econômica (DMEE) de N calculadas para 20 situações distintas de solo, cultura antecessora e dose de $\mathrm{N}$ indicada. Esses resultados corroboram a adequação do sistema de indicação de $\mathrm{N}$ para alta produtividade de milho na região.
Outro respaldo importante ao sistema de indicação de $\mathrm{N}$ proposto é o bom ajuste que as doses indicadas para a região centro-sul do $\mathrm{PR}$ apresentaram em relação às doses indicadas para o $\mathrm{RS}$ e $\mathrm{SC}\left(\mathrm{R}^{2}=0,88\right.$, $\mathrm{p}=0,02$; Figura 7b), em condições similares de teor de MO do solo, cultura antecessora e faixa de rendimento (Amado et al., 2002; Comissão..., 2004).

Quadro 2. Indicação de N para a cultura do milho no sistema plantio direto na região centro-sul do Paraná

\begin{tabular}{|c|c|c|c|c|}
\hline \multirow{2}{*}{ Pré-cultura e teor de $\mathrm{MO}^{(1)}$} & \multicolumn{4}{|c|}{ Expectativa de rendimento de grãos $\left(\mathrm{t} \mathrm{ha}^{-1}\right)$} \\
\hline & $6-8$ & $8,1-10$ & $10,1-12$ & $12,1-14^{(4)}$ \\
\hline $\mathrm{g} \mathrm{kg}^{-1}$ & 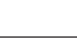 & 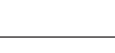 & & \\
\hline \multicolumn{5}{|l|}{ Gramíneas } \\
\hline$<40$ & 100 & 150 & 220 & 300 \\
\hline $41-60$ & 60 & 110 & 180 & 260 \\
\hline$>60$ & $\leq 40$ & 70 & 140 & 220 \\
\hline \multicolumn{5}{|l|}{$\begin{array}{l}\text { Consórcio gramínea - } \\
\text { leguminosa ou nabo forrageiro }\end{array}$} \\
\hline$<40$ & 60 & 110 & 180 & 260 \\
\hline $41-60$ & $\leq 40$ & 60 & 130 & 210 \\
\hline$>60$ & $\leq 40$ & $\leq 40$ & 90 & 180 \\
\hline \multicolumn{5}{|l|}{ Leguminosas } \\
\hline$<40$ & $\leq 40$ & 60 & 130 & 210 \\
\hline $41-60$ & $\leq 40$ & $\leq 40$ & 80 & 160 \\
\hline$>60$ & $\leq 40$ & $\leq 40$ & $\leq 40$ & 130 \\
\hline
\end{tabular}

(1) Teor de MO referente à camada de $0-10 \mathrm{~cm} \cdot{ }^{(2)} \leq 40 \mathrm{~kg} \mathrm{ha}^{-1}$ corresponde à dose de $\mathrm{N}$ a ser aplicada por ocasião da semeadura do milho. ${ }^{(3)}$ Aplicar uma dose de $20 \mathrm{~kg} \mathrm{ha}^{-1}$ de $\mathrm{N}$ menor do que a indicada em situações em que a pré-cultura gramínea apresentar baixa produção de biomassa $\left(<2 \mathrm{t} \mathrm{ha}^{-1}\right)$. Em situações em que o milho suceder consórcio gramínea-leguminosa ou nabo forrageiro

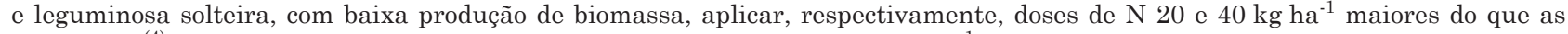
indicadas. ${ }^{(4)}$ A coluna referente à expectativa de rendimento de $12,1-14$ t ha ${ }^{-1}$ deve ser restrita a lavouras nas quais todos os demais aspectos relacionados ao manejo do solo (fertilidade e físico), manejo da cultura (população, tratamentos fitossanitários, controle de ervas daninhas, etc.) estejam otimizados e a previsão de volume de chuvas seja igual ou superior à média normal para o período de desenvolvimento da cultura.
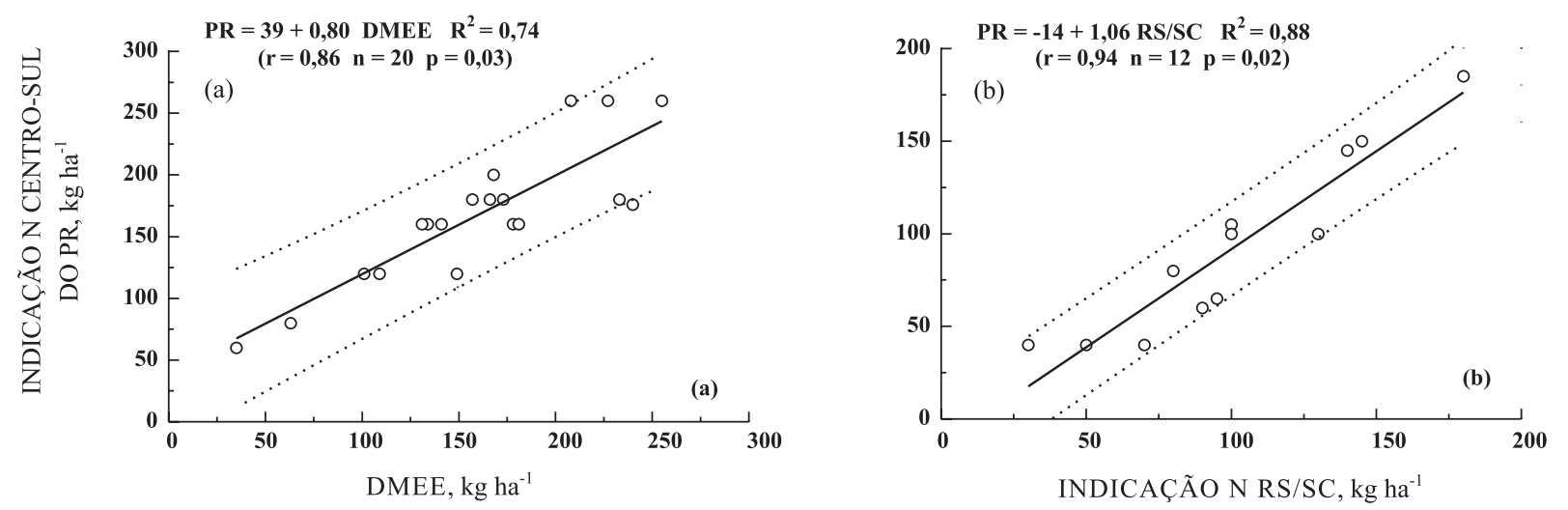

Figura 7. Relação entre as doses de máxima eficiência econômica (DMEE) de N as doses indicadas no quadro 1 (a), e entre a indicação de N do RS/SC e a indicação para a região centro-sul do PR (Quadro 2) para condições similares de solo, cultura antecessora e faixa de rendimento (b). As linhas tracejadas representam o intervalo de confiança de $95 \%$ da equação ajustada. 
Essa boa relação entre a indicação de $\mathrm{N}$ para a região centro-sul do PR e para os Estados do RS e SC é muito importante, pois valida a utilização desta indicação, a qual é ajustada para elevadas faixas de rendimento, para sub-regiões do RS e de SC com alto potencial de rendimento do milho. Por outro lado, a indicação do RS e SC, a qual apresenta faixas mais baixas de rendimento, também é válida para ser utilizada em sub-regiões do PR, em que os rendimentos do milho estejam em faixas mais baixas do que as verificadas neste estudo. Portanto, a análise conjunta da indicação para o centro-sul do PR apresentada e da indicação em vigor para os estados do RS e SC demonstra o caráter complementar que pode ser adotado no uso dessas indicações, equacionando praticamente a indicação de N para milho na região Sul do Brasil.

\section{CONCLUSÕES}

1. O sistema de indicação de $\mathrm{N}$ para o milho desenvolvido com base na demanda de $\mathrm{N}$ para diferentes faixas de rendimento da cultura, na capacidade de suprimento de $\mathrm{N}$ do solo pela matéria orgânica, no efeito da planta de cobertura antecessora na disponibilidade de $\mathrm{N}$, e na eficiência do $\mathrm{N}$ aplicado via fertilizante mineral, mostrou-se adequado conforme evidenciado pela significativa relação entre as doses indicadas de $\mathrm{N}$ com as doses de máxima eficiência econômica de $\mathrm{N}$ para a cultura do milho.

2. A boa relação entre as indicações de $\mathrm{N}$ para a região centro-sul do PR e para os Estados do RS e SC valida o uso da indicação do PR, a qual apresenta faixas de rendimento de milho mais elevadas em sub-regiões do RS e SC com alto potencial de rendimento da cultura, assim como valida o uso da indicação do RS e de SC em sub-regiões do PR com menor potencial produtivo.

\section{AGRADECIMENTOS}

Os autores expressam agradecimento à Equipe da Fundação Agrária de Pesquisa Agropecuária (FAPA) e, em especial, aos técnicos Renato Paulo de Moraes, Antonio Sandro de Lima Rodrigues e Adão Paulo Rodrigues; ao Engenheiro Agrônomo Carlos Andrés Leguizamón Rojas (PPG Ciência do Solo, UFRGS) e aos estudantes de Agronomia (UFRGS) e bolsistas do CNPq Fernando Vieiro e Tiago Soares Pedroso, pela assistência técnica na execução da pesquisa; aos Cooperados Ervin Stock, Karl Eduard Milla e Paul Illich pela cessão das áreas e apoio na condução dos experimentos; aos pesquisadores da FAPA e agrônomos da assistência técnica da Cooperativa Agrária Agroindustrial, pelas sugestões e colaboração na execução dos experimentos ao longo dos 13 anos de pesquisa; ao conselho nacional de Desenvolvimento Científico e Tecnológico - CNPq pelo suporte à pesquisa e à bolsa de produtividade (C. Bayer).

\section{LITERATURA CITADA}

AITA, C.; CERETTA, C.A.; THOMAS, A.L.; PAVINATO, A. \& BAYER, C. Espécies de inverno como fonte de nitrogênio para o milho no sistema de cultivo mínimo e feijão em plantio direto. R. Bras. Ci. Solo, 18:101-108, 1994.

AITA, C.; GIACOMINI, S.J.; HUBNER, A.P.; CHIAPINOTTO, I.C. \& FRIES, M.R. Consorciação de plantas de cobertura no outono/inverno antecedendo o milho em plantio direto: Dinâmica do nitrogênio no solo. R. Bras. Ci. Solo, 28:739749, 2004.

AMADO, T.J.C.; MIELNICZUK, J. \& AITA, C. Recomendação de adubação nitrogenada para o milho no RS e SC adaptada ao uso de plantas de cobertura do solo, sob sistema plantio direto. R. Bras. Ci. Solo, 26:241-248, 2002.

AMADO, T.J.C.; MIELNICZUK, J. \& FERNANDES, S.B.V. Leguminosas e adubação mineral como fontes de nitrogênio para o milho em sistemas de preparo do solo. R. Bras. Ci. Solo, 24:179-189, 2000.

AMADO, T.J.C.; MIELNICZUK, J.; FERNANDES, S.B.V. \& BAYER, C. Culturas de cobertura, acúmulo de nitrogênio total no solo e produtividade de milho. R. Bras. Ci. Solo, 23:679-686, 1999.

ANGHINONI, I. Adubação nitrogenada nos Estados do Rio Grande do Sul e Santa Catarina. In: SIMPÓSIO SOBRE ADUBAÇÃO NITROGENADA NO BRASIL, Ilhéus, 1984. Anais. Ilhéus, Sociedade Brasileira de Ciência do Solo, 1984. p.51.

BAYER, C. \& FONTOURA, S.M.V. Dinâmica do nitrogênio no solo, pré-culturas e o manejo da adubação nitrogenada na cultura do milho em plantio direto. In: FONTOURA, S.M.V. \& BAYER, C., eds. Manejo e fertilidade de solos em plantio direto. Guarapuava, Fundação Agrária de Pesquisa Agropecuária, 2006. p.59-85.

BAYER, C. \& MIELNICZUK, J. Nitrogênio total de um solo submetido a diferentes métodos de preparo e sistemas de cultura. R. Bras. Ci. Solo, 21:235-239, 1997.

BAYER, C. Dinâmica da matéria orgânica em sistemas de manejo de solos. Porto Alegre, Universidade Federal do Rio Grande do Sul, 1996. 240p. (Tese de Doutorado)

BAYER, C.; MIELNICZUK, J. \& PAVINATO, A. Sistemas de manejo do solo e seus efeitos sobre o rendimento do milho. Ci. Rural, 28:23-28, 1998.

CARTER, J.N.; WESTERMANN, D.T. \& JENSEN, M.E. Sugar beet yield and quality as affected by nitrogen level. Agron. J., 68:49-55, 1976.

COMISSÃO DE QUÍMICA E FERTILIDADE DO SOLO CQFS-RS/SC. Manual de adubação e de calagem para os Estados do Rio Grande do Sul e de Santa Catarina. 10.ed. Porto Alegre, Sociedade Brasileira de Ciência do Solo, 2004. 400p.

EMPRESA BRASILEIRA DE PESQUISA AGROPECUÁRIA EMBRAPA. Centro Nacional de Pesquisa de Solos. Sistema brasileiro de classificação de solos. Brasília, 1999. $412 \mathrm{p}$. 
FERNANDES, S.B.V. Disponibilidade e eficiência de uso do nitrogênio pelo milho em sistemas de cultura. Porto Alegre, Universidade Federal do Rio Grande do Sul, 1998. 137p. (Tese de Doutorado)

FONTOURA, S.M.V. \& BAYER, C. Adubação nitrogenada para alto rendimento de milho em plantio direto na região Centro-Sul do Paraná. Guarapuava, Fundação Agrária de Pesquisa Agropecuária, 2008. 32p.

FONTOURA, S.M.V. Adubação nitrogenada na cultura do milho em Entre Rios, Guarapuava, Paraná. Guarapuava, Fundação Agrária de Pesquisa Agropecuária, 2005. 94p.

FONTOURA, S.M.V.; BACK, S.P.; ZIMMER, C.R. \& MORAES, R.P. Evolução e fertilidade atual do solo da região CentroSul do Estado do Paraná, sob plantio direto. In: REUNIÃO BRASILEIRA DE FERTILIDADE DO SOLO E NUTRIÇÃO DE PLANTAS. 26., Lages, 2004. Anais. Lages, UDESC, 2004. CD ROM.

FREITAS, V.H.; ROSSO, A.; BAYER, C. \& MIELNICZUK, J. Efeito de métodos de preparo de solo e sistemas de cultura na absorção de nitrogênio e rendimento do milho. R. Pesq. Agropec. Gaúcha, 2:69-77, 1996.

GIACOMINI, S.J.; AITA, C.; CHIAPINOTTO, I.C.; HUBNER, A.P.; MARQUES, M.G. \& CADORE, F. Consorciação de plantas de cobertura antecedendo o milho em plantio direto: Nitrogênio acumulado pelo milho e produtividade de grãos. R. Bras. Ci. Solo, 28:751-762, 2004.

INSTITUTO AGRONÔMICO DO PARANÁ - IAPAR. Cartas climáticas. Disponível em: <http://200.201.27.14/Site/Sma/ Cartas_Climaticas/Precipitacao.htm> Acesso em 24 jan. de $2008 \mathrm{a}$.
INSTITUTO AGRONÔMICO DO PARANÁ - IAPAR. Médias de temperatura. Disponível em: <http://200.201.27.14/Site/ Sma/Estacoes_IAPAR/Estacoes_Parana.htm> Acesso em 24 jan. de 2008b.

LOVATO, T.; MIELNICZUK, J.; BAYER, C. \& VEZANNI, F.M. Carbono e nitrogênio adicionados e sua relação com o rendimento do milho e estoques destes elementos no solo em sistemas de manejo. R. Bras. Ci. Solo, 28:175-187, 2004.

MIELNICZUK, J.; BAYER, C.; VEZZANI, F.M.; LOVATO, T.; FERNANDES, F.F. \& DEBARBA, L. Manejo de solos e culturas e sua relação com os estoques de carbono e nitrogênio do solo. In: CURI, N.; MARQUES, J.J.; GUILHERME, L.R.G.; LIMA, J.M.; LOPES, A.S. \& ALVAREZ V., V.H. Tópicos em ciência do solo. Viçosa, MG, Sociedade Brasileira de Ciência do Solo, 2003. v.3. p. 209-248.

PARR, J.F. Chemical and biochemical considerations for maximizing the efficiency of fertilizer nitrogen. J. Environm. Qual., 2:75-82, 1973.

SECRETARIA DA AGRICULTURA E DO ABASTECIMENTO DO PARANÁ - SEAB. Agricultura - Área e Produção. Disponível em: <http://www.seab.pr.gov.br/arquivos/File/ deral/epcpr.xls> Acesso em 24 jan. de 2008.

SPAGNOLLO, E.; BAYER, C.; WILDNER, L.P.; ERNANI, P.R.; ALBUQUERQUE, J.A. \& NADAL, R. Análise econômica do uso de leguminosas estivais intercalares à cultura do milho, na ausência e na presença de adubação nitrogenada, no oeste de Santa Catarina. R. Bras. Ci. Solo, 25:709-715, 2001.

STANFORD, G. Rationale for optimum nitrogen fertilization in corn production. J. Environ. Qual., 2:159-166, 1973. 